\title{
Precariedad y violencia. Representación(es) de la inmigración en el teatro de México*
}

\author{
Hugo Salcedo Larios ${ }^{1}$ \\ Universidad Iberoamericana (Ciudad de México)
}

\section{Resumen}

La frontera norte de México es un escenario real donde se propicia un encuentro a veces violento, de fuerzas equidistantes, complejas y contradictorias. Es punto nodal en el tránsito de personas y mercancías que lo convierten en auténtico vertedero de aspiraciones truncas. Resumen de anhelos, imaginarios y frustraciones, arraigo de identidades y añoranzas por los distanciamientos geográficos; choque cultural y lingüístico. Es a través del teatro, ya desde sus características aristotélicas o bien como manifestación de las formas posdramáticas consistentes en la exposición autobiográfica, la ruptura lógica convencional, la narración dramática, etcétera, que se presenta una de las expresiones idóneas que ofrecen este contexto liminal de contradicciones. En este sitio, señala por ejemplo Alejandro Lugo, la vida cultural se modifica y reproduce a partir de estas contingencias y situaciones históricas-culturales, como una reacción a la arbitraria pero férrea constitución del poder legi-

\section{Abstract}

The northern border of Mexico is a real scenario where it leads to a sometimes-violent encounter, equidistant, complex and contradictory forces. It is a nodal point in the movement of people and goods that make the authentic aspirations truncated dump. Overview of longings, frustrations, imaginary and rooting of identities and longing by the geographical distances; cultural and linguistic shock. Is through the theater, because from Aristotelian characteristics or as a manifestation of the forms posdramaticas consisting of autobiographical exposure, the conventional logical breakdown, dramatic narration, etc., presented one of the suitable expressions that provide this liminal context of contradictions. On this site, for example says Alejandro Lugo, cultural life is modified and reproduced from these contingencies and Reconstructions situations, as a reaction to the railway but arbitrary Constitution of power politically legitimized by central Governments and their institu-

\footnotetext{
* Insecurity and violence. Representation (s) of the immigration in the theater of Mexico

1 Doctor en Filología por la Universidad Complutense de Madrid. Académico de tiempo completo de Universidad Iberoamericana, Ciudad de México. Correo electrónico: hugo.salcedo@ibero.mx
} 
timado políticamente por los Estados centrales y sus instituciones.

En la década de los años noventa del siglo pasado, estas condiciones fueron propicias para el surgimiento del denominado «Teatro del Norte» como una posibilidad de organización de colectivos o creadores independientes que dieron lugar a textos y montajes importantes. Esta cualidad de organización del gremio teatral se ha continuado ya entrada la nueva centuria ofreciendo trabajos de excelente factura. La intención del presente artículo es poner a consideración algunos de los textos dramáticos que dejaron la huella de un importante teatro regional o fronterizo con las características antes anunciadas.

Palabras clave: Teatro mexicano, inmigración, frontera, violencia, representación. tions. In the Decade of the nineties of the last century, these conditions were conducive to the emergence of the so-called «Teatro del Norte» as a possibility for collective organization or independent artists that resulted in texts and important assemblies. This quality of organization of the Theatre Guild has continued already input the new century featuring works of excellent invoice. The intention of this article is to consider some dramatic texts, which left the mark of an important regional or border with previously announced features theatre.

Keywords: Mexican theatre, Immigration, Border, Violence, Representation.

\section{Dramaturgia del norte de México}

En razón de su calidad y pertinencia temática, la literatura dramática y sus derivaciones escénicas producidas en la zona norte de México han cobrado reconocimiento nacional y en el extranjero. Estas producciones señalan diferentes tipos de violencia extrema, mediante el planteamiento de las situaciones precarias de quienes habitan o transitan por ese territorio en su intento de ingresar a los Estados Unidos. Las marcas de tensión en el tránsito y convivir fronterizo de sus habitantes, se aprecia en los tratamientos teatrales de los autores.

Fue en el norte mexicano, tan lejano de la capital del país y por ello mismo un tanto desprotegido de una política cultural centralista, el lugar donde se desarrolló una manera novedosa de organización gremial. Ya entrada la década de los años noventa, las iniciativas aisladas de algunos creadores se sumaron hasta convertirse en un auténtico movimiento que practicó otras formas de producción dramática y escénica, cuyos productos estéticos rebasaron los límites del ámbito local. El crítico inglés Peter Beardsell apunta el año de 1998, fecha en que apareció el primer volumen de la serie Teatro del norte cuya publicación fue auspiciada por los propios autores incluidos. En 
este libro se dio constancia de la calidad de la obra dramática escrita en la región. Abunda Beardsell (2006) al señalar que: "Naturalmente, ya se conocían varios de los cinco dramaturgos representados en la colección por las piezas que habían puesto en México y en el extranjero [...], pero desde la publicación de la antología se formó cierta identidad colectiva" (9). Efectivamente fueron cinco los autores participantes de aquella primera edición. Ellos coincidieron también en organizarse mediante una forma que tuviera más relación con sus entornos culturales específicos, sociales y hasta geográficos, buscando la gestión de espacios propios a fin de solventar las acotadas políticas centralizadas emanadas desde la ciudad de México.

Estos dramaturgos que también poseían el perfil de profesores universitarios, habían practicado la dirección escénica de sus propias obras y de otros autores. La cualidad de experimentación formal les proporcionó un elemento de atracción escénica en la búsqueda de nuevos espectadores. En muchos de los casos sus obras escritas o dirigidas, van a tener en cuenta una revisión crítica de ciertos pasajes de la historia nacional como la Revolución, o el uso de personajes mitológicos presentados en contextos fronterizos reconocibles mediante procesos de deconstrucción. En sus propuestas, sin embargo, va a estar presente el sentido del aislamiento y ensimismamiento de los personajes que "se manifiesta en un descontento innato, el cual se expresa en [el gran esfuerzo por alcanzar] un objetivo inasequible" (Beardsell, 2006: 11).

En general los ambientes propuestos para el desarrollo de las historias dramáticas van a ser hostiles a los personajes como un reflejo de la realidad acuciante. La violencia se va a manifestar de maneras muy diversas pero siempre como una barrera que impide la realización de los sueños más preciados, sean ya en aras de una mejor posición económica o como parte de una aspiración de motivación inconsciente.

La intención de este ensayo es anunciar estrategias de composición dramática presentes en algunos textos dramáticos que hacen referencia a esa geografía. Por este camino se pretenden advertir ciertas condiciones económicas, políticas y sociales del entorno fronterizo de México con el país del norte, que menoscaban la calidad de vida de sus habitantes. La selección de los materiales creativos considerados en este artículo es solo una acotada muestra del importante caudal de propuestas que se escribieron -y que se siguen escribiendo. En ellos puede observarse su pertinencia social que desvela los rostros de la violencia, las situaciones de discriminación y orfandad de sus vecinos. Como podrá verse, los autores tienen muy en cuenta dibujar el entorno de referencia que se traduce en tratamientos 
realistas o simbólicos, con el afán de clarificar la denuncia ante la indefensión de los personajes.

\section{La violencia dramática en la frontera: Bustillo Oro y Rascón Banda}

“Las relaciones culturales -señala Alfonso Alfaro (1999)- entre México y los Estados Unidos están marcadas por la historia y por la geografía: son sumamente intensas, las caracteriza una profunda asimetría y poseen una enorme variedad de ocasiones de malentendido" (3). Y es que la relación histórica de interdependencia de México con el país vecino del norte, ha ido presentando una multiplicidad de rostros y manifestaciones que construyen imaginarios que trascienden la expectativa local de la búsqueda de mejores condiciones de vida. Estas características edifican una amplia carpeta de referencias temáticas y estéticas que han encontrado en su forma de literatura dramática o espectáculo escénico, una de sus mejores oportunidades de expresión.

El espacio geopolítico de la frontera norte mexicana se erige como auténtico escenario en donde hay un encuentro violento de fuerzas equidistantes, complejas y contradictorias. Es punto nodal, antes solo de tránsito como el vertedero de aspiraciones truncas, pero ahora también como plaza de llegada. Resumen de anhelos, imaginarios y frustraciones. Arraigo de identidades, añoranzas y desprecios por las distancias geográficas y la hostilidad que plantea a su vez un choque cultural y lingüístico.

A lo largo de más de ciento sesenta años de historia, las políticas internas y bilaterales de las dos naciones en cuestión, así como la vida cotidiana en ambos lados de la frontera, han ido determinando un estadio de conectividad: más de rechazo que de aceptación a políticas migratorias, y de poco grata convivencia. Esta relación está marcada también por asuntos complejos y comunes como los de medio ambiente, las aguas internacionales, la vida comercial, educación y salud, sin olvidar por supuesto los diversos rostros de la violencia derivados del tráfico de personas, armas y estupefacientes.

Por un lado, la franja simboliza un bien perdido, herencia de la fractura de orden histórico y político, y la acumulación de nuevas problemáticas compartidas; pero también representa, a su vez, la esperanza y punto de tránsito obligado para quienes pretenden ingresar a nuevas y-se entiende que- mejores oportunidades de vida, fincando así una compleja dialéctica de atracción y de rechazo.

De esta manera, como señala Alejandro Lugo (2003), la vida cultural que se presenta en ese espacio geográfico específico, se modifica 
y reproduce a partir de estas contingencias y situaciones histórico-culturales, como una reacción a la arbitraria pero férrea constitución de poder legitimado políticamente por los Estados centrales y sus instituciones (81).

Quizá sea por la naturaleza de esta zona en contacto que las expresiones culturales de diversa índole como las artes plásticas, la música o el video, han ido construyendo un lugar idóneo para hacer experimento. En ese tenor, la dramaturgia y el performance han sido también disciplinas de inmejorable producción que ponen en juego la exploración a partir de sus propios canales y lenguajes.

Ya desde los años treinta del siglo pasado, cuando Juan Bustillo Oro publicó en Madrid su texto dramático Los que vuelven (1933), la frontera mexicana va a ser considerada como un territorio agreste y peligroso. En palabras de su autor, este drama se presenta como: "[una] epopeya de la repatriación entre los hombres sin patria, a quienes la dura ley capitalista condena implacablemente a sucumbir cuando no necesita su trabajo" (Bustillo, 1933: 1). El tratamiento determinista de la pieza va a condenar la maquinaria de explotación de la oferta de trabajo inmigrante.

La "pieza trágica" escrita en tres tiempos, desarrolla sus dos partes iniciales en territorio estadounidense. La primera sucede en la finca triguera de una compañía industrial cuya construcción contrasta con la pequeña casa de techo de lámina, una choza casi, en donde vive la familia García. Ellos alquilan su mano de obra en la factoría. Los integrantes de la familia siempre se van a referir con sentida nostalgia al distante lugar de origen que tuvieron que abandonar en búsqueda de trabajo. Los progenitores se recriminan constantemente la decisión tomada. Remedios por ejemplo, le espeta a su marido: "No me cansaré de repetirlo, aunque tú te canses de oírlo... Es tu pecado... El habernos arrancado como plantitas de nuestra tierra húmeda para aventarnos a las máquinas de los extraños... Haberle traído huesos a que alimente tierra que no es la suya" (Bustillo, 1933: 23). Parece entonces que la decisión de emigrar ha sido determinada por el padre de familia, en cuyo caso ni los hijos ni la esposa han podido evitar. La insatisfecha mujer, aun cuando permanece al lado del esposo, lo hace culpable de todas las desgracias. El primer acto concluye cuando la especulación en el mercado del grano obliga a quemar la cosecha y los hombres son despedidos de la fábrica. El resplandor del fuego aparece como el símbolo de la angustia y de la injusticia que sufren los trabajadores.

La familia de esta historia prefiere continuar en el exilio y decide, antes que regresar a la ciudad del sur de donde partieron, viajar a 
la ciudad del norte para ir en busca de la hija casada con un gringo. Pero la llegada fortuita al departamento de los Kerr, no es afortunada. Guadalupe, la hija desposada ahora con el estadounidense, relata la falta de trabajo y las continuas redadas que realizan los agentes de la migración para deportar a los extranjeros. La molestia del yerno por la llegada de los viejos en tan difíciles condiciones económicas, concluye con la denuncia ante la autoridad de que sus propios suegros están en el territorio de forma irregular. Con este aviso, la policía pasará por ellos y los devolverá en el siguiente ferrocarril que ya va de regreso a México.

El tercer tiempo está marcado con un determinismo de orden naturalista en donde los hijos serán quienes paguen las culpas de los padres. Esta parte de la obra se desarrolla en un campamento improvisado del lado mexicano, muy cercano a la frontera. Los hombres se refugian en el tequila y las notas de guitarra. Todos recuerdan los excelsos bienes perdidos. Con pesar rememoran a los hijos o a la mujer amada. Se presienten como en un espacio sin nombre, en una suerte de purgatorio que determina su vida sin futuro cierto en donde se suceden los “días y días de penar..." (Bustillo, 1933: 71) como menciona uno de los personajes. Para alguno de ellos la autoinmolación va a ser la única alternativa a fin de concluir con la retahíla de congojas.

La melancolía inunda la vida de estos hombres que no tienen nombre ni apellido. Ellos se presentan en el libreto como el "Hombre de la guitarra" o "El del suelo", por ejemplo, mostrando en ese lastimero anonimato la pesadumbre colectiva. Ya se refugian en el abuso de alcohol o en la marihuana. El viejo de la obra pierde a su mujer quien fue víctima de una epidemia. Y al apreciarse completamente solo, pretende atacar a un militar para que éste le provoque la muerte y al fin encontrar la paz. En la dolorosa y al tiempo feliz agonía, expresa: "Que me pongan muy hondo en la tierra, en una tierra regada donde haya árboles..." (Bustillo, 1933: 81) porque el anciano rehúye a la cremación y porque quiere finalmente convertirse en alimento de las raíces. Sin embargo, apenas muere ya se ordena llevarlo ante el montón de otros cadáveres para que le prendan fuego y evitar la expansión de la peste. Tampoco el último deseo suyo se realiza ni aún después de la muerte. No solo ha fallado su afán de progreso económico y de reagrupación familiar, sino también de encontrar reposo de acuerdo a sus creencias.

Marcela del Río (2018) hace notar la influencia del teatro expresionista del director de escena alemán Erwin Piscator en este drama de Juan Bustillo Oro: "especialmente, en la introducción de los rompimientos de la acción, y finales de cada "tiempo" o acto, con escenas en las que un coro, o dos coros (alternados) intercalan sus comenta- 
rios sobre la acción, enfatizando los momentos climáticos con juegos de luz" (29).

Deviene en esta forma artística también una crítica contra el capitalismo y sus prácticas mercantiles que desde una perspectiva marxista lo observan como la raíz de los males sociales. En la pieza es utilizado de manera elocuente el lenguaje metafórico, como cuando se hace constante mención a la quema del trigo y las diferencias entre la tierra fértil y la estéril; el fuego es la fuerza aplastante que no solo destruye el alimento del hombre sino también a los mismos hombres.

Parece entonces que la enseñanza final de esta obra es, como menciona Del Río, que "no debemos traicionar nuestra tierra, sino trabajarla y defenderla, y no irnos al extranjero a ser despreciados y a que nos asesinen" (Del Río, 2018: 30). El tratamiento expuesto en esta obra permite una visión peculiar de los inmigrantes, quienes pretenden a ultranza dar seguimiento a sus propias costumbres aún dentro de un espacio físico que les resulta ajeno y al que no pueden -pero tampoco quieren- adaptarse.

Como resultado de este choque de fuerzas, al ambiente romántico, determinista y pleno de nostalgia sobrevendrá el desenlace trágico. Posterior al cierre de la fábrica, los trabajadores van a ser expulsados del país. El angustioso trance provoca el suicidio como alternativa única a la que algún desesperado recurre.

Ya para 1979, Víctor Hugo Rascón Banda propondría su texto Los ilegales cuya dedicatoria contiene un trasfondo político encuadrado en una mirada pesimista: "A los trabajadores indocumentados que, víctimas de un injusto sistema económico y obligados por el hambre, cruzan la frontera del Norte de México y encuentran en el otro lado solamente humillaciones, robos, lesiones... y si bien les va, la muerte" (Rascón, 2004: 33). Este carácter desesperanzador se refuerza en la exposición dramática mediante los recursos propiamente didácticos que se apoyan, por ejemplo, en el personaje denominado como el "Informante", trabajador indocumentado que entona al público sus canciones y recita extractos de las notas de prensa y bibliográficas. Este recurso pretende ilustrar de manera objetiva la vejación y el sacrificio de los inmigrantes en el empeño por alcanzar su meta.

En conjunto, la obra expone las vicisitudes de tres parejas de migrantes provenientes de diferentes puntos de México (del norte, del centro y del sur o de la costa) que por motivos diversos intentan abandonar sus distintos lugares de origen e ingresar a los Estados Unidos. Los seis personajes conservan sus nombres propios de uso común: 
José, Jesús, Lupe o Lola, por ejemplo, en contraposición con una amplia carpeta de personajes de ambientación que tienen cabida en la zona fronteriza del lado mexicano: niños que piden limosna, turistas norteamericanos, meseras, desempleados, enganchadores, contratistas; y de otras entidades que aparecen en el lado estadounidense: trabajadores agrícolas indocumentados, predicadores, granjeros texanos, agentes de migración, y hasta miembros de cierta secta religiosa. Con unos y otros se pretende configurar el paisaje cotidiano fronterizo que sin embargo cae aquí en el dibujo un tanto esquemático, al presentar generalidades del carácter y de las características de los personajes que retrata.

Aparecen otros elementos de contraposición como el desarrollo del primer acto "En este lado: México", y el segundo en "El otro lado", o sea los Estados Unidos. En la primera de las partes (que se desarrolla en las diversas poblaciones de origen de los migrantes y en Ciudad Juárez), se exhiben las condiciones nacionales de expulsión de la fuerza de mano de obra, y la atracción por el ingreso a la economía vecina en donde el imaginario económico hace crecer las expectativas del candidato inmigrante. La segunda parte tiene lugar en territorio estadounidense: en los campos de cultivo, en las barracas donde pernoctan los trabajadores y en alguna cantina donde desahogan sus penas. La obra concluye con la persecución y tortura de los mexicanos en manos de un grupo de encapuchados.

El autor hace referencia así a varios sucesos como el registrado en 1977, poco tiempo antes de que la obra fuera conocida, cuando los miembros de una secta, en nombre de la fortaleza, la pureza y la supremacía de la raza blanca, efectuaron atentados, atracos y quemas de viviendas. Se representan también a los indocumentados que fueron torturados ese mismo año, por el granjero George Hannigan y sus dos hijos, en el estado de Arizona.

Una férrea alambrada se impone en la escena. Hacia el final de la obra decenas de trabajadores sin documentos permanecen agrupados debajo de un puente mientras escuchan las noticias de ese momento histórico en las que se anuncia la reducción considerable en la expedición del número de visas anuales para los mexicanos. El noticiero informa de las propuestas del entonces presidente Jimmy Carter (1977-1981) quien restringe la entrada de los trabajadores inmigrantes. Con esta disposición gubernamental va a incrementarse la fuerza policíaca fronteriza caracterizada por un alto nivel de agresividad, implementando también una política fiscal que derivará en una mayor sangría a los ingresos de los indocumentados. 


\section{Otras modalidades de representación de la violencia}

El investigador Francisco Beverido Duhald (2010) considera que el paisaje entendido como contexto geográfico, va a incidir en la determinación de la elección temática y los tratamientos estilísticos de sus autores dramáticos. En un estudio suyo enfocado a la producción del norte de México, señala que: "El desierto y el mar son quizá los símbolos más impresionantes de las fuerzas de la naturaleza, y de la fragilidad del hombre en su eterna lucha contra ella. Son dos extremos ante los cuales la voluntad, la potencia y la decisión humanas, llegan a fracasar" (107). Lo anterior tiene amplio sentido si se considera la acción del personaje dramático bajo el patrón aristotélico en donde debe sortear diversos obstáculos en su afán de alcanzar su objetivo. En ese sentido, el contexto problematiza y dificulta sus aspiraciones.

Sin embargo, no solo la geografía entorpece el tránsito de los inmigrantes, pues todavía más acuciante va a ser la violencia resentida desde renglones como el secuestro para el cobro de rescates o el reclutamiento en las filas criminales, el tráfico de personas y estupefacientes, las redadas y detenciones arbitrarias, el cobro ilegal a manera de "derecho de piso" para los comerciantes, la lucha entre los cárteles de la droga, los desplazamientos forzados, las violaciones, etcétera.

En continuidad a estos señalamientos, va a publicarse la sintética pero emblemática partitura dramática titulada Amarillo (2013) de Gabriel Contreras que se trata, para ser consecuentes con la propia definición de su autor, más de una propuesta escénica que de un texto dramático propiamente dicho; más cercana al performance que a un montaje escénico convencional. La obra fue estrenada por Jorge Arturo Vargas para el colectivo "Teatro Línea de Sombra", representada en varios foros nacionales y del extranjero.

En la puesta de Amarillo, ubicada prioritariamente en el desierto texano y de cuya pequeña localidad toma nombre, se presenta un complejo espectáculo en donde la brevedad del texto que cabe en apenas nueve páginas impresas, se soluciona mediante una fusión de imágenes y sobre posiciones. El montaje va a resultar de gran atracción visual, producto del complejo y acertado cruce interdisciplinario: los actoresbailarines interpretan coreografías que fusionan el baile popular y la danza contemporánea, al tiempo que proyecciones de diversos formatos y motivos son muy aprovechadas de la multimedia. También hay un alejamiento a la disposición espacial estática y unívoca, fruto de los bidones de agua que se vacían, la arena que lentamente cae en delgados hilos desde sus bolsas rotas, las reiteraciones del trazo y 
movimiento corporal de los actores, sus mutaciones, los saltos contra la pared del muro que divide la frontera, etcétera.

El director escénico construye una representación en la que "el personaje y el paisaje se funden en uno solo. Los personajes no son individuos, no son un hombre o una mujer, sino todos los hombres y mujeres que cruzan la frontera, o se quedan esperando [en ella]" (Talavera, 2013: 16). A nivel discursivo se hace referencia a la muerte recurrente que ha producido cientos de cadáveres a lo largo de la historia migratoria, de los trenes que atraviesan el horizonte como una metáfora del progreso que se ha desvanecido, de la imaginería popular plagada de santones o ánimas en pena, y el intento por asirse al bienestar económico.

Amarillo se ubica, más que un texto dramático, como un producto escénico que puede resumir no solamente la inquietud temática de precariedad y violencia a que se alude en este artículo, sino también que muestra las posibilidades de resoluciones estéticas mediante la incorporación de lenguajes que se dirigen de forma muy atractiva e ingeniosa a los espectadores.

Por otra parte, el drama La cubeta de los cangrejos (2016) de Juan Carlos Embriz está integrado por catorce escenas, cortísimas y de alto voltaje que se suceden como una rápida descarga. Encontramos en el texto personajes reconocibles, multiplicidad de espacios que van desde la Terminal de Autobuses en Toluca, ciudad localizada en el centro de México, hasta un barrio de Los Ángeles en California. Aun cuando aquí está presente la distancia de los espacios físicos para llevar a cabo las acciones dramáticas, la violencia y el desamparo serán también la pátina que recubre las acciones de los personajes.

La obra incorpora interlocutores con nombre propio que remiten a escenas e historias cotidianas en el ya recurrente tránsito de indocumentados justo en la franja fronteriza del norte, pero también ubica a inmigrantes anónimos, traficantes humanos de origen méxico-estadounidense, a los que se suma la vara flamígera de los llamados minutemen que a balazos o mediante denuncias, impiden el ingreso de mexicanos y de otros países latinoamericanos. Entre todos ellos se construye no ya una frontera porosa sino más bien un espacio infranqueable, erigido como la barrera divisoria que refuerza la división política entre las naciones como una certeza estúpida de que el ingreso a los Estados Unidos debe estar prohibido a toda ultranza.

El esfuerzo de los personajes colocados en la hostilidad de las circunstancias hace que duden profunda y profusamente de su tránsito: "Ya no sé si voy o vengo" (Embriz, 2016: 121), expresa Amelia en su intento por localizar a su hijo perdido. 
Se eleva el tono trágico y de efectos confusos cuando esta mujer muestra el papel que la identifica, porque el documento que debiera ser su partida de nacimiento y que consulta de continuo para no olvidarse de su nombre, resulta ser en realidad su propia acta de defunción. Esta revelación la convierte en espectro deambulatorio, en un espíritu que ya olvidó si murió de hambre, de frío, a tiros, o fue comida por animales salvajes. “Aquí dice que usted está muerta!”, expresa sorprendida Elvira cuando lee el escrito; pero la respuesta de Amelia es contundente: “¿Y cuándo he dicho que estoy viva?" (Embriz, 2016: 132), le contesta. Y por más, ese sentimiento no sólo se refiere a la muerte física del cuerpo, sino también al desarraigo y la discriminación de mexicanos en el país vecino, como cuando Juan el Gato se expresa: "Andar por acá es como andar muerto, porque sientes que apestas" (Embriz, 2016: 129).

Lo indistinto es que el fenómeno migratorio no sólo convoca a los individuos con capacidades intelectuales limitadas, sino que también alcanza a la población de estudiantes y profesionistas que no encontraron sitio en el ámbito laboral de sus propios países.

La dialéctica de atracción y rechazo de mano de obra entre ambas sociedades marcada por la necesidad imperante, es la que aprovecha el "pollero" o traficante de personas. Él es quien sale con ganancias económicas al imponer altas cuotas para servir de guía burlando los controles migratorios, aunque en ocasiones él mismo representa el peligro como cuando conduce al grupo hacia la extorsión y el abuso que ejecutan sus compinches. El "pollero" sin embargo no muere, se reconstruye y replica como un mal necesario, como una pieza fundamental del engranaje de la miseria social y económica.

La obra titulada Arde Fénix (2010) de Agustín Meléndez Eyraud presenta pocos personajes que, por esto mismo, permiten una más directa identificación con el espectador. La acción se desarrolla en un espacio cerrado único: se trata de un centro de detención de inmigrantes en Phoenix, Arizona. Allí podemos ser testigos de las condiciones en que se llevan a cabo tales detenciones desde el martirologio administrativo que es ejemplo de la larga cadena de injusticias, chantajes y vejaciones no ya sólo contra los ciudadanos en tránsito, sino también en el propio devenir laboral. Dos agentes latinos de la migra (un hombre y una mujer) hacen alarde del protocolo puesto en práctica en la captura, encarcelamiento y deportación, mientras esperan la resolución un joven detenido y un enigmático hombre en silla de ruedas.

El diálogo que se va desdoblando sin contratiempo, permite visualizar y dar consistencia a estos personajes bien trazados. Son dibujos 
de la deshumanización del hombre desplazado y de la concepción de una suerte de "raza superior" que bajo el escudo de una supuesta legitimidad, ya atropella, viola y aniquila.

Uno de los puntos clave de esta pieza es la discusión racista que se deriva del simple tono de la piel, el color de los ojos y el cabello, luego también en la ejercitación del inglés como lengua dominante y global, y finalmente en la cualidad de ciudadanía o el estatus migratorio de la persona. Los cuatro personajes que intervienen en Arde Fénix, pertenecen al escalón más bajo de este podio discriminatorio; y aún en él se acentúan las diferencias puesto que, como se dice en la obra, no va a ser lo mismo haber nacido en Estados Unidos (aunque de padres mexicanos allegados a ese país en condición migratoria desconocida) que haber sido naturalizado, estigmatizándose ambos casos como ciudadanos de segunda categoría.

También llama la atención el tono de supremacía machista que el Agente masculino impone sobre su compañera femenina, cuando le confiesa las particularidades necesarias para llegar a ser un funcionario de verdad, con la "digna" altura que el cargo confiere: Primero, le dice: "Tienes que ser hombre. Tienes que tener pito. Tienes que tener un pene. Un chile. Si no tienes pito o no tienes chile no eres un verdadero agente"; y eso porque: "Las mujeres sólo sirven para llenar formas. Para la enfermería. Para ayudar a los hombres. Para servir a los hombres" (Meléndez Eyraud, 2009: 16). Ya hacia el final del texto se da a conocer el auténtico secreto del éxito para llegar a ser un verdadero agente: "[se debe] sentir ODIO. [El secreto] Es ODIAR a todos. ODIAR con toda tu alma sobre todas las cosas. El que no ODIA no alcanza la GLORIA" (Meléndez Eyraud, 2009: 28).

En la diatriba previa al cierre de la obra, se establece un atractivo juego verbal en donde se condenan mutuamente los personajes: él por el hecho de ser mexicano y ella doblemente, tanto por ser mexicana como por ser mujer.

Al final el provocador y liberador incendio arrasa con los papeles condenatorios que descansan en el escritorio, y es entonces cuando el detenido escapa por uno de los cristales rotos. Una hora después, sin embargo, el espacio habrá de ser nuevamente acondicionado por otros trabajadores de mantenimiento a quienes se les advierte de su condición de mexicanos, o sea invasores o alienígenas, mientras el supervisor de origen blanco les espeta las últimas palabras, antes que llegue el último oscuro: "Fucking mexicans!", les grita.

El fénix aniquilado vuelve como en la mitología, a resurgir de sus propias cenizas, iniciando otra vuelta de odio y discriminación racial. 
A la pregunta planteada al autor respecto a las motivaciones de escritura de esta pieza, éste expresó lo siguiente:

\begin{abstract}
Esta obra es una oportunidad para que el público sea testigo de lo que millones de inmigrantes sufren todos los días. La brutal realidad del odio racial generado por un problema migratorio. [...] ¿Acaso este odio racial no es el mismo que comenzó miles de años atrás y continuó hace poco cobrando la vida de millones de judíos durante la Segunda Guerra Mundial? ¿Qué sigue? ¿Qué otro holocausto tiene preparado el demonio en su mundo de tinieblas? (Meléndez Eyraud, 2010: 3).
\end{abstract}

El dramaturgo opina que a la Ley SB-1070 del Estado de Arizona que según él se acordó para hacer dinero, debido al nutrido negocio de captura y encarcelamiento de inmigrantes. Advierte la reacción en los lectores y espectadores de su pieza quienes, explica:

podrá[n] sentir la impotencia ante una situación injusta que se repite sin medida. Podremos informarles con este documento sobre la injusta vida en las cárceles de inmigrantes propagadas por todo el terreno de los Estados Unidos. No hay nada en esta obra que sea mentira" (Meléndez Eyraud, 2010: 6).

Desde la instauración de la actual línea fronteriza en el siglo diecinueve, y hasta 1924, el trazo de la "nueva" frontera entre Estados Unidos y México "permaneció prácticamente libre de vigilancia, y la migración fluía con libertad" (Chomsky, 2014: 22). Fue en 1965 cuando los mexicanos, tan solo serlo, estaban exentos de las restricciones migratorias hechas luego ley, acentuando la aparente paradoja que persiste hasta nuestros días, respecto a la imagen de los Estados Unidos como un país de inmigrantes de todas partes del mundo, y por otro lado su xenofobia y sus políticas migraciones restrictivas (Chomsky, 2014: 22).

Numerosas leyes se han puesto en práctica desde el siglo pasado a la fecha. En esta cuenta están, por ejemplo el Programa Bracero de 1942 a 1964 que reclutó a millones de mexicanos para trabajar por temporada; la Operación Wetback o "espaldas mojadas" que hace referencia a los cruces por el Río Bravo convertido a su vez en cementerio de mexicanos y de otros países; la Ley de Seguridad de 1950 que creó la green-card o tarjeta verde para el tránsito cotidiano de ida y vuelta a los puestos de trabajo; la Operación Guardián de 1994 que incluyó la construcción de un muro; el despliegue masivo de agentes 
de la Border Patrol por la autovía construida para efectos de vigilancia militar; la instalación de torres de iluminación con lámparas tipo estadio y el sobrevuelo de aparatos no tripulados para el control exhaustivo; hasta la denominada Ley Dream del siglo veintiuno, propuesta y abandonada varias veces en el ámbito federal (Chomsky, 2014: 193-194) y que como se sabe, se encuentra actualmente en crisis con el advenimiento de la era Trump. Así entonces, los proyectos de regularización de inmigrantes han presentado complejas y paradójicas circunstancias, acompañadas en muchos de los casos por las políticas de deportaciones masivas, nuevas disposiciones legales para controlar los ingresos a ese territorio, los desplazamientos de la ruta de inmigrantes a zonas de cruce más peligrosos, las persecuciones, discriminaciones y amenazas.

En alguno de estos sentidos, las aportaciones al teatro hechas por Gerardo Navarro no son poco elocuentes, pues sus propuestas causan desasosiego sórdido, inquietud temática y fascinación en su forma de exposición. Pienso en aquella prístina entrega publicada a finales de la década de los años noventa, titulada Hotel de cristal (1997) en donde se perciben algunas de sus particularidades, como hace con el uso del spanglish o espanglés el personaje dramático fronterizo que navega sin asidero posible, en una consistencia de múltiples formas; pero sus hallazgos no los realiza mediante un estéril experimento lingüístico, sino como el retrato de una modalidad emergente o quizá valdría decir mutante. En esa obra, la violencia como trazo indeleble es la constante que aflora inmisericorde. Allí hay gruñidos, pieles tatuadas, tortura, chasquidos de lengua, ripios poemas escritos con navaja, recipientes llenos de orines viejos que conducen a la eficaz ambientación y tránsito por los infiernos: desde la irreverencia clerical al sádico canibalismo ejecutado de un personaje contra otro.

Otras propuestas de este autor como Schizoethnic o Sparky G (El gitano fronterizo) (2003) resumen sus preocupaciones estéticas del cruce cultural binacional, de las identidades que mediante este inevitable movimiento se ponen en contacto. Estas obras presentan la confusión ciertamente hasta esquizoide, en un mundo globalizado, disforme y al tiempo transgresor. Con esta última pieza Gerardo Navarro confeccionó un espectáculo unipersonal en donde él mismo se convirtió en el intérprete, logrando conectar adecuadamente con su propio texto, exponiendo las posturas ideológicas que este contiene. En el montaje quedaron resumidas sus preocupaciones referentes al cruce binacional en la frontera más transitada del mundo.

Ahora bien, la aparición del primer libro individual de este dramaturgo, da lugar a su obra dramática titulada Yonke humano (2009), que refuerza el trabajo que Navarro ha ido realizando mediante una multi 
e interdisciplinariedad que lo caracteriza: en una ciudad del tercer milenio transitan por la delgada línea de la existencia, un abanico de seres en principio contrarios pero que, como en un modelo para armar, se requieren unos a otros para mostrar en su conjunto el panorama urbano de necedad, corrupción, asesinato y podredumbre.

La factura caricaturesca aporta un tono de burla, denuncia y al tiempo de urgente escapatoria ante la impotencia civil que se respira en ciudades del norte de México en donde los habitantes son víctimas cotidianas en el ambiente precario que les rodea.

\section{Papá está en la Atlántida}

Debido a su importancia como texto dramático, y en razón de los últimos visos de la política antiinmigrantes de Donald Trump en los Estados Unidos, mención aparte merece la obra Papá está en la Atlántida (2006) de Javier Malpica.

La escritura de esta pieza va a dar cuenta de otro de los rostros de la violencia en el flujo migratorio y que, quizá por marcado rasgo de indefensión, va a mostrar su cara más agresiva. Y es que los menores de edad también sufren la experiencia propia de la desventura, como tan prematuramente lo expone esta obra compuesta por diez escenas que permiten, mediante el diálogo fresco y preciso, ir reconstruyendo la imagen de los ausentes: la abuela, el papá y la madre muerta en primer plano; pero también la figura de la amiga Graciela, de los primos, de la maestra, de los tíos. De manera pausada e ingenua, el diálogo descubre la travesía de los únicos personajes que intervienen en el drama, y que resultan ser los dos hermanitos de once y ocho años en su propio viaje al norte mexicano: desde la capital del país hasta el desierto en Arizona, al ansiado reencuentro con su padre que se ha ido en busca de trabajo.

Se trata de una obra que, si bien redunda en el aspecto migratorio como motor de su historia, lo hace con la mínima presencia del lenguaje didascálico. Acrecienta la velocidad de los hechos mediante las rupturas temporales y los saltos de la historia, dando prioridad a los reiterados silencios de los personajes como grandes incógnitas a resolver por parte del espectador.

El texto involucra directamente al lector mediante la exposición temática de la práctica migratoria que aquí se expone, y lo jalona mediante el uso del humor sutil que se deja escuchar entre estos huérfanos de madre y desarraigados de todo. Tanto el sentido de extrañeza y la "no-pertenencia" a los lugares de llegada como la necesidad vital de reunirse con su progenitor en Atlanta, lleva a los pequeños per- 
sonajes a desafiar los peligros individuales y enfrentar los riesgos del tránsito por espacios de paso y situaciones inhóspitas que en su periplo se les presentan.

No es ajena en esta pieza la ironía triste percibida como una constante de manera que el más chico de los hermanitos (el de 8 años) confunde el destino de su padre: "Mi papá está en la Atlántida [...] un lugar maravilloso donde toda la gente era feliz" (Malpica, 2010: 2223). El más pequeño confunde la ciudad de Atlanta en Estados Unidos, con la mítica Atlántida; y a la aclaración que le hace su hermano mayor (el de 11 años) ve cómo se derrumba la idea que se hacía del padre como protagonista de un relato maravilloso. Remarco la corta edad de los protagonistas para intentar resaltar la tesitura del texto que se construye en ese vaivén que oscila entre la inocencia propia de la infancia y la crudeza de los hechos a los que deben desventuradamente enfrentarse. Luego de los intentos fallidos por hacerse de un lugar amable en la casa de la abuela o al lado de los primos, los hermanos se trepan a un autobús que los hace cruzar todo el Estado de Sonora.

Con un ambiente de ambigüedad concluye la pieza, subrayada por la violencia contenida que precisa la desgracia que va a ocurrir en la penumbra del desierto. Allí, los niños se enfrentan a la soledad, a las inclemencias del tiempo y muy probablemente a la muerte física que se anuncia en la forma del delirio que ellos se inventan para soñar una mítica tierra feliz:

$<: ~ ¿$ Sabes qué más hay en Atlanta además de albercas por todos lados?

>: Dímelo.

$<$ : Hay juegos como los del parque. Y de comer siempre hay pastelitos. Y malteadas de chocolate.

>: Qué padre.

$<$ : Y todos los días y todas las noches pasan películas. (Malpica, 2010: 50).

Este juego muestra el imaginario que los dos pequeños han construido en torno a una mítica ciudad feliz y abundante. Sin embargo, al cierre de la obra, las vocecitas van perdiendo intensidad hasta que concluye la escena en la oscuridad y el silencio absolutos.

El texto se expresa mediante la modernidad de la forma; es decir, a través de la experimentación del recurso literario que en este caso 
se refleja en el uso mínimo de las acotaciones, la dinámica de la secuencia discursiva, la economía de los personajes, la contundencia de las acciones y la potenciación de los silencios que incrementan la tensión dramática.

Esta obra de Javier Malpica refleja la situación de urgencia por el desempleo que motiva la inmigración y la consecuente fractura del núcleo familiar y el abandono de los progenitores, que a su vez conduce a los infantes a su propio intento de inmigrar para reunirse con ellos. En este carril cabe la denuncia de María Cristina Perceval, directora regional de UNICEF para América Latina y el Caribe quien señala que en esta región: "hay 6.3 millones de niños, niñas y adolescentes que son migrantes o refugiados [y que] 100.000 niños no acompañados fueron detenidos en la frontera entre México y Estados Unidos entre 2015 y 2016" (Perceval, 2017: 1). Este problema global hace altamente vulnerables a los infantes quienes además, ante el desconocimiento del inglés y de las leyes, se convierten en víctimas de maltrato, explotación sexual, trabajo forzado, abuso de autoridad, deportación o encarcelamiento.

Pero hay más, pues apenas en el mes de junio de 2018 fue creciente la indignación internacional por la separación de los miembros de las familias migrantes en la frontera sur de Estados Unidos. El propio senador estadounidense Bernie Sanders en su cuenta de Twitter, según informa el diario La vanguardia, colocó un video probablemente grabado en un antiguo almacén de McAllen, Texas, en donde se aprecian los rostros y se escucha el llanto de niños centroamericanos retenidos y literalmente enjaulados, como resultado de la política de "tolerancia cero" de la administración Trump en la frontera. Dice Sanders en el audiovisual:

La administración Trump, en su crueldad descarada, está forjando un lugar único en la historia de Estados Unidos. No es solo el apoyo al racismo, el sexismo, la homofobia, la xenofobia y el fanatismo religioso, han alcanzado un nuevo mínimo al separar a los niños de sus padres y colocarlos en centros de detención. ( $L a$ vanguardia, 2018: 1).

El periódico arriba señalado apunta también que el gobierno estadounidense ha apartado casi dos mil niños de sus padres desde finales del mes de abril de 2018, después de que el Fiscal General de Estados Unidos Jeff Sessions, anunciara la política que incluye redadas masivas, además de la imputación de cargos penales a todos los inmigrantes capturados y la separación de las familias. La 
administración Trump se sacude la responsabilidad y atribuye falsamente la práctica a una ley de la era del presidente Barack Obama (2009-2017), durante la cual en circunstancias extremas también se separaba a las familias. El gobierno estadounidense ha empezado a presentar cargos contra todas las personas que crucen ilegalmente la frontera. Mientras los padres esperan la resolución del juicio, los niños son apartados de sus familias y trasladados a centros de menores (La vanguardia, 2018: 1).

\section{Conclusiones}

El abrevadero temático que presenta la producción dramática de la zona septentrional da cuenta de los distintos rostros de la inmigración hacia los Estados Unidos; sin embargo, esta enunciación ha permitido también a autores residentes en otros puntos de México, interesarse en la escritura de textos dramáticos con esta temática. En conjunto los dramaturgos van a referirse a las motivaciones de los personajes, sus circunstancias o peripecias de viaje, a partir de imaginarios individuales o colectivos como la bonanza económica en el país norteño que va a propiciarles un mejor porvenir a ellos y sus familias, pero el peligro y la frustración opacarán su esfuerzo.

Desde el terreno de la ficción los autores divisan las profundidades y contornos de este fenómeno histórico, actualizando las novedades del tránsito forzoso y siempre violento no como una particularidad perpetua entre ambas naciones, sino con alcances globales en tanto la inmigración le resulta inherente a la humanidad en su conjunto. La frontera entre las dos economías se presenta como la barrera a traspasar, a fin de alcanzar mejores condiciones de vida que los propios ciudadanos migrantes en sus países de nacimiento no alcanzan.

Sin embargo, para los autores dramáticos que persiguen denunciar estas modalidades se enfrentan a la hidra de múltiples cabezas, en sentido tal que lo novedoso está en la forma de narrar los acontecimientos y sus circunstancias, porque como menciona Manuel Talavera (2013), "los temas de la frontera no se agotan mientras haya formas distintas de abordarlos" (16) y mientras, claro está, persistan las condiciones de pobreza ahora imperantes.

Aún con la agenda del gobierno estadounidense en contra, vale mencionar al cierre de este trabajo el continuo afán de los autores dramáticos que construyen sus textos considerando la ambición de cruzar fronteras. En este proceso escritural y escénico, de continuo aparecen también tratamientos de corte histórico, imaginario o mítico, sin abandonar el sentido de precariedad y los rostros de la 
violencia. Los dramaturgos retratan problemas de relaciones e intimidades humanas y eternas como en todo el mundo, teniendo en cuenta demás que, como menciona Aviva Chomsky:

\begin{abstract}
Las fronteras que separan a los migrantes de Estados Unidos no son únicamente físicas. Una vez dentro del país -ya sea por medio de un cruce fronterizo traumático o por haber excedido el plazo de la visa- las personas sin documentos viven otro tipo de frontera, una frontera confusa y a veces atemorizante que los separa de aquellos que los rodean y del país y la sociedad en la que viven (Chomsky, 2014: 105).
\end{abstract}

A lo anterior se añaden por supuesto los tópicos de la inseguridad e incertidumbre entre las personas inmigrantes, ante la distancia geográfica con sus familiares y los afectos.

Complejidad y paradoja en esta inmigración que se encamina a unos territorios que antes, según se lee en la historia, fueron mexicanos. Los personajes del teatro, como miles de ciudadanos reales, viven la expulsión por las limitaciones laborales en los lugares de nacimiento. Expulsión también como resultado de la violencia y el narcotráfico que los hace encaminarse a la búsqueda de mejores e ideales condiciones de vida. Ellos se proyectan hacia una visión de futuro bajo el dibujo de una realidad que es dolorosa, difícil y precaria. Resienten la tristeza como una marca del vacío de la existencia y la sensación de no estar del todo en ninguno de los dos sitios, mientras el extendido dicho popular es siempre mutante y acomodaticio: "Tan lejos de Dios y tan cerca de los Estados Unidos".

\title{
Bibliografía
}

Alfaro, A. (1999). México-EEUU, las rutas de la cooperación. México: Secretaría de Relaciones Exteriores - Instituto Matías Romero - ITAM.

Beardsell, P. (2006). Teatro del norte: identidad consolidada. En: Salcedo, Hugo. Teatro del Norte 6. Tijuana: Teatro del Norte Universidad Autónoma de Baja California.

Beverido Duhald, F. (2001). Arena, Mar y Desierto: El paisaje como personaje en la joven dramaturgia del norte de México. En: Frontera Norte / South Border. Ciudad Victoria: Fondo Regional para la Cultura y las Artes del Noreste.

Bustillo Oro, J. (1933). Tres dramas mexicanos: Los que vuelven. Masas. Justicia, S. A. Madrid: Cenit. 
Chomsky, A. (2014). Indocumentados. Cómo la inmigración se volvió ilegal. Ciudad de México: Ediciones Culturales Paidós.

Contreras, G. (2013). Amarillo. En: Manuel, Talavera. Territorio Teatral. Siete del septentrión mexicano. Chihuahua: Universidad Autónoma de Chihuahua.

Délano, A. (2014). México y su diáspora en Estados Unidos. Las políticas de emigración desde 1848. México: El Colegio de México.

Del Río, M. (2018). Los que vuelven de Juan Bustillo Oro. Revisado el 26 de junio de 2018 desde Internet: http://www.reneavilesfabila.com.mx/universodeelbuho/107/05_letras.pdf

Embriz, J. C. (2016). La cubeta de los cangrejos. Toluca: Gobierno del Estado de México.

Herrera Carassou, R. (2006). La perspectiva teórica en el estudio de las migraciones. México: Siglo Veintiuno.

Lugo, A. (2003). Reflexiones sobre la teoría de la frontera, la cultura y la nación. En: Scott, Michaelson, y David E., Johnson. Teoría de la frontera. Los límites de la política cultural. (270 pp.). Barcelona: Gedisa.

Malpica, J. (2010). Papá está en la Atlántida. Monterrey: CONARTE Nuevo León - Universidad Autónoma de Nuevo León.

Marroni, M. G. (2009). Frontera perversa, familias fracturadas. Puebla: Benemérita Universidad Autónoma de Puebla.

Meléndez Eyraud, A. (2009). Arde Fénix. Texto dramático inédito.

Meléndez Eyraud, A. (2010). Respuesta electrónica al cuestionario elaborado por Hugo Salcedo, 21 de agosto, inédito.

Perceval, M. C. (2017). El drama de los niños migrantes no acompañados. Arena pública. Revisado el 4 de octubre de 2017 desde Internet: http://arenapublica.com/articulo/2017/06/09/5962/100000-ninos-migrantes-no-acompanados-detenidos-en-frontera-mexico-estados

Ramos Tovar, M. E. (2009). Migración e identidad: emociones, familia, cultura, México: Fondo Editorial de Nuevo León.

Rascón Banda, V. H. (2004). Los ilegales. En: Teatro de frontera $13 /$ 14. Víctor Hugo Rascón. (562 pp.). Durango: Siglo XXI - Conaculta - UJED - Espacio Vacío Editorial.

Talavera Trejo, M. (2013). Prólogo. En: Territorio Teatral. Siete del septentrión mexicano (284 pp.). Chihuahua: Universidad Autónoma de Chihuahua. 
Un vídeo muestra a los niños 'enjaulados' en la frontera con EE.UU. La vanguardia. Revisado el 9 de julio de 2018 desde Internet: http://www.lavanguardia.com/internacional/20180619/45267919977/video-ninos-enjaulados-eeuu.html

Vázquez, J. Z. y Lorenzo Meyer. (2013). México frente a Estados Unidos. Un ensayo histórico, 1776 - 2000. México: Fondo de Cultura Económica. 